\title{
El Bowery fotografiado por Martha Rosler
}

\author{
Ramón Laurentino Redondo Velasco \\ The Bowery photographied by Martha Rosler
}

\begin{abstract}
RESUMEN:
Estudio de la instalación fotográfica de Martha Rosler acerca de un barrio deprimido de Nueva York, titulada El Bowery en dos sitemas de representación inadecuados (1975), y exposición de las reflexiones de la artista sobre la capacidad del medio fotográfico para convertirse en herramienta política.

PALABRAS CLAVE: fotografía documental, arte crítico, espacio público, crisis urbana, representación, experiencia, sociedad, Bowery, Martha
\end{abstract}

Rosler.

Study of Martha Rosler's photo-installation concerning a deprived neighbourhood in New York, entitled The Bowery in two inadequate descriptive systems (1975), and presentation of the artist's reflections on the ability of photography to become a politcal tool.

KEYWORDS:

documentary photography, critical art, public space, urban crisis, representation, experience, society, Bowery, Martha

Rosler.

Martha Rosler es conocida por su obra artística en la que aborda la cuestión de género, sin embargo ha trabajado también con acierto sobre los espacios público y privado. Lectora en los sesenta y setenta de Engels, Arendt, Habermas, Debord y, con más atención, de Lefebvre, fue construyendo una idea de la ciudad contemporánea en la cual el debate público ha ido degenerando hacia un mero consumo pasivo de medios de información en el ámbito privado, dejando la puerta abierta a la programación del deseo y su consecuente normalización de la sociedad'. Quizá hacia 1968 no le pareciera un panorama tan desalentador cuando, como consecuencia de la tensión social acumulada, comenzaron a sucederse las rebeliones en diferentes puntos del mundo capitalista. Pero, como ya se sabe, pese a que algunas de ellas lograron una situación propicia para las reivindicaciones de ciertos movimientos sociales, el auténtico problema de fondo no se resolvió. No consiguieron cambiar el sistema, ni siquiera derribar a los gobiernos allí donde sucedieron². Terminadas las revueltas, Rosler pudo leer a Foucault, Deleuze y

1 ROSLER, M.: Imágenes públicas: La función política de la imagen, Barcelona, Gustavo Gili, 2007, p. 237.

2 Al margen de sus lecturas, reconoce la fuerte influencia que ejercieron sobre ella los disturbios sociales de los sesenta, marcando decididamente su obra. Idem, p. 22. Consultar también ROSLER, M.: «Si 
Guattari, quienes coincidieron con Lefebvre en el mismo año 1972 en argumentar posibilidades de reorientación tras el fracaso. Mientras otros tiraron la toalla 0 , como Debord, mantuvieron su postura previa a las rebeliones, estos autores tomaron nota de la experiencia para inventar nuevos tipos de barricada: Si un gran vuelco no era posible, se intentaría una sucesión de pequeños cambios. De todo esto a Rosler le quedó conciencia de que el arte debía tener utilidad social, coincidiendo con otros artistas coetáneos de Norteamérica y Europa en un segundo intento de llevar el arte a la vida, pero esta vez de forma menos idealista que las vanguardias de principios de siglo, proponiendo metas modestas en entornos locales.

Al poco de mudarse a Nueva York pudo conocer la situación del Bowery, un barrio cercano a su casa que se estaba haciendo muy popular por ser uno de los más deprimidos de la ciudad. El tratamiento que recibía de los medios, haciendo de él un espectáculo, sólo ayudaba a marginarlo. Rosler decidió implicarse con este problema y, así, lo llevó al terreno del arte con la intención de inducir a una reflexión más pausada. En 1975, expuso por primera vez The Bowery in two inadequate descriptive systems ${ }^{3}$, una instalación en la que combina textos e imágenes subrayando la incapacidad de ambos para tratar la experiencia del barrio. La obra es resultado de una planificación que ella misma ha ido diseccionando en entrevistas y ensayos.

A su juicio, un paso previo a cualquier intervención siempre debe ser recabar información sobre el tema a tratar. Evitar la actitud irresponsable de quienes disparan sobre conflictos ajenos sin preocuparse antes por conocerlos, confiados en la objetividad de sus cámaras.

Ella vio un Bowery repleto de borrachos haciendo vida en la calle. Pudo saber que, en su mayoría, se trataba de los mismos vecinos con limitados recursos que habían sobrevivido en sus pisos hasta pocos años antes, cuando las subidas de impuestos y rentas de alquiler les obligó a desalojarlos. Su vagabundeo por un barrio destartalado empezaba a ser objetivo de los medios, con lo que el ayuntamiento de la ciudad decidió tomar cartas en el asunto. Pero lo hizo con un ambicioso proyecto de reconstrucción urbanística que afectó a algunos otros barrios además del Bowery. Las autoridades públicas, aparentemente preocupadas por el bienestar social, justificaban esta operación razonando que su deterioro urbanísti-

vivieras aquí», pp. 175 y 178, en VV.AA.: Modos de hacer. Arte crítico, esfera pública y acción directa, Salamanca, Universidad de Salamanca, 2001, pp. 173-203. Este artículo es una revisión por la autora de su ensayo "Fragments of a metropolitan viewpoint", en WALLIS, B (ed.): If you lived here. The city in art, theory, and social activism. A project by Martha Rosler, Nueva York, Bay Press y DIA Art Foundation, 1991, pp. 15-45.

3 El Bowery en dos sistemas de representación inadecuados. Ese año lo expuso en el ICA de San Francisco. A Europa llegó en 1981 con motivo de la 5 $5^{\text {a }}$ Bienal Internacional de Viena, en el marco de la exposición Fotografía Expandida que tuvo lugar en el Centro Secession de Viena (Austria). En España pudo verse en la individual que el MACBA dedicó a la artista entre 1999 y 2000 titulada Posicionamientos en el mundo real y, más recientemente, en el Centro José Guerrero de Granada dentro de Martha Rosler. La calle, la casa, la cocina celebrada en 2009. La obra está a la venta en galerías, como la parisina Anne de Villepoix. 
co estaba destruyendo moralmente a sus habitantes. Sin embargo, pese a que la desmoralización era evidente, no lo era tanto que se debiera al aspecto de sus calles. Ya venía observándose desde hacía tiempo como un proceso paralelo a la conversión de la economía productiva en financiera. Y es que la desindustrialización gradual que ese cambio implicó, llevaba dos décadas dejando en paro a trabajadores obsoletos para el nuevo modelo económico. Este era el caso de quienes ocupaban el Bowery, un barrio obrero varado en pleno centro de una ciudad en expansión ${ }^{4}$. Pero las víctimas no importaron tanto al ayuntamiento como las cuentas de la ciudad, seriamente endeudada 5 . Los diversos poderes -económicos en su mayoría - atribuyeron la deuda a un exceso de gasto público, lo que sirvió de excusa para recortar servicios sociales que las clases más pudientes no utilizaban. Una estrategia que ha sido bautizada como «recorte planificado» y que perseguía animar, a esas comunidades de bajos o nulos ingresos que aún resistían en el centro, a buscar residencia fuera de él ${ }^{6}$. Así, el barrio deteriorado y casi abandonado se convirtió en blanco de especuladores inmobiliarios que, comprando a buen precio, sacaron beneficios tras una fase de reconstrucción que parecía justificada. Esto repercutía positivamente en el erario público vía impuestos. Los edificios que no eran sustituidos por oficinas o sedes corporativas de las nuevas compañías, eran rehabilitados según la moda del momento y ocupados por una clase media alta, capaz de pagar los elevados tributos necesarios para rellenar las arcas municipales.

Se trata de una explicación sobre la situación del Bowery que muchos ciudadanos desconocían.

Tras esa labor previa de investigación Rosler encuentra necesario elegir el modo de intervención más eficaz, entendiendo que es una cuestión de responsabilidad no exponer un problema ajeno si no es para ayudar a resolverlo.

Como fotógrafa, ella planeó una actualización del documental, cuya capacidad narrativa le parecía especialmente útil para este caso. Pensó que era la manera

\footnotetext{
${ }^{4}$ Sobre la distribución del espacio en función del modelo productivo consultar ROSLER, M.: «Si vivieras...», pp. 175-180.

5 He recogido este enfoque de CANDELA, I.: Sombras de ciudad. Arte y Transformación Urbana en Nueva York, 1970-1990, Madrid, Alianza, 2007, pp. 83-86, quien lo desarrolla a partir de dos análisis que tuvieron amplia aceptación pública. TABB, WK y SAWERS, L (eds.): Marxism and the Metropolis: New perspectives in urban political economy, Nueva York, Oxford University Press, 1978, p. 242. SMITH, N y WILLIAMS, P (eds.): Gentrification of the City, Boston, Allen \& Unwin, 1986, pp. 204-224. Rosler trata también la cuestión, pero existe cierta contradicción entre lo que expone en «Si vivieras...», pp. 181 y ss. y lo que escribe trece años después en Imágenes públicas..., p. 10.

6 Migración que a su vez se ha denominado «gentrificación». Lefebvre lo define como un proceso por el cual, en un determinado espacio, se sustituye a su población original por una clase económica más alta. LEFEBVRE, H.: Espacio y política. El Derecho a la Ciudad II, Barcelona, Península, 1976, pp. 102, 123,140 y ss. Engels adelantó un siglo este concepto, aunque no empleara ningún término concreto para definirlo. Lo detectó en París, con las intervenciones de Haussmann a mediados del siglo XIX, pero también en Londres, Berlín y otras grandes ciudades europeas. ENGELS, F.: Contribución al problema de la vivienda, Moscú, Progreso, sin fechar (195X), pp. 19, 72 y ss, 151. Benjamin hizo también su aportación. BENJAMIN, B.: Libro de los pasajes, Madrid, Akal, 2007, p. 148.
} 
más indicada para ocuparse de una calle que no la configuran tanto la apariencia de sus fachadas, sino las experiencias humanas que entre ellas suceden. Sin embargo, quería esquivar esa tendencia del género a exponer la miseria frente a espectadores pasivos, por lo que vio necesario buscar estrategias visuales que probó en esta misma obra.

Consta de veinticuatro paneles. Cada uno muestra una fotografía junto a un texto sobre un fondo de pizarra negra, excepto los tres primeros, que carecen de imágenes. Casi siempre se han expuesto distribuidos en cuadrícula, como secuencias de una misma historia. Según explica la autora, esto obedece a cuatro motivos: connota rigurosidad al remitir a una organizada estética de archivo; cuestiona el concepto de límite e incluso tiende a superarlo, pues da la impresión de que podría haber más piezas; rechaza la idea de artículo único de lujo al aludir a la producción en serie; y atempera la tendencia emotiva de la fotografía, ofreciendo la frialdad necesaria para abordar la cuestión social críticamente.

Por su parte, la elección del medio fotográfico se debió a que le parecía idóneo para recoger documentos gráficos directamente de la realidad y con relativa inmediatez. Esto le confiere una supuesta objetividad que, si no es del todo cierta, al menos el espectador sí otorga a la fotografía 7 . Le interesó, además, que por entonces fuera aún considerada un género artístico menor, una opción vulgar que permitía un mayor grado de experimentación ${ }^{8}$. Lo cual explica la factura improvisada que puede apreciarse aunque, por otra parte, parezca contradecir su pretensión de rigurosidad. Pero es que, más que una obra de arte, ella concibió este proyecto como un trabajo de investigación que, además, dejó abierto para que otros artistas continuasen.

Rosler tomó las fotos que integran la obra en dos días de diciembre de 1974, a la hora en que echaban el cierre las pocas tiendas que quedaban ya en el barrio. Muestran una calle deteriorada. Salvo un par de planos cenitales, el resto son frontales de fachadas, escaparates, soportales... casi todos carentes de perspectiva y deliberadamente inexpresivos, siguiendo un modo de hacer que recuerda bastante a las tipologías del matrimonio Becher. Además, parece recoger rasgos estilísticos de la fotografía de actualidad, como el encuadre espontáneo y el uso del blanco y negro. Pero, sobre todo, se trata de un guiño a la tradición realista documental norteamericana de los años treinta ${ }^{9}$. En las fotos se reconoce a Evans por su manera de centrar la atención en la gente, más que en el espacio que ocupan. Tam-

\footnotetext{
7 Hasta tal punto es así que, como demostró Godard, la veracidad de las imágenes es prescindible en un documental objetivo. ROSLER, M.: Imágenes públicas..., pp. 244-249.

8 BUCHLOH, B y ROSLER, M.: «Una conversación con Martha Rosler», p. 42, en DE ZEGHER, C (ed.): Martha Rosler: Posiciones en el mundo real (cat. exp.), Barcelona, Actar, 1999, pp. 23-55.

9 Sobre todo a la Farm Security Administration, dependiente del Departamento de Agricultura de los Estados Unidos, a la que se encarga un amplio estudio de campo para valorar las condiciones de vida de los habitantes en el medio rural del país. Entre otros fotógrafos de renombre Walker Evans trabajó para ella y, al hilo de esta experiencia aunque inicialmente por encargo de la revista Fortune, publicó algunas fotos acompañando el texto de un periodista. AGEE, J. y EVANS, W.: Elogiemos ahora a hombres famosos, Barcelona, Seix Barral, 1993.
} 
bién puede detectarse su influencia en la importancia que concede a los intervalos de las secuencias, aquello que no podemos ver. Los recursos que más le atrajeron de esa tradición documental fueron, en un principio, la narración de la historia y la representación de sus protagonistas. Aunque pronto desestimó precisamente esto último para evitar una nueva explotación de las víctimas ${ }^{10}$. Prefirió enseñar el escenario urbano del que se acababan de ausentar, mostrando sólo las huellas de su paso reciente. Sustituyendo a los borrachos por botellas abandonadas aún con alcohol, siguió hablando de ellos sin necesidad de exponerlos. Una ausencia que además simboliza su carencia de voz: como sucede a menudo, a falta del discurso de los marginados se estaba imponiendo el que los diferentes poderes confeccionaron a la medida de sus intereses, por lo que pocos ciudadanos conocían las causas del problema ${ }^{11}$.

Del documental le interesaba, además, su capacidad para transformar lo específico en algo genérico, permitiendo extrapolar reflexiones a situaciones similares pero distantes temporal o geográficamente.

No estando de acuerdo con la falta de espíritu crítico del documental liberal que se hacía en el momento, junto con Allan Sekula, Fred Lonidier y Phil Steinmetz formuló un «nuevo documental radical». Para ello no sólo buscaron en la tradición propia de los años treinta, sino también fuera, entre otros el cine ruso de Eisenstein y el que hacía por entonces Godard en Francia. El grupo distinguía dos «momentos» en la fotografía: el inmediato, que carga a la imagen de contenido histórico; y el momento estético, relativo exclusivamente a los aspectos formales. A todas luces se inclinaban por el primero e incluso pretendían obviar el segundo, demasiado vinculado a una autonomía del arte que ellos rechazaban. Preferían analizar la realidad desde el testimonio gráfico para incitar a una reflexión susceptible de provocar, a su vez, acciones de mejora. Querían hacer un «arte representacional crítico» ${ }^{12}$.

Rosler lo ensayó con este proyecto sobre el Bowery, el cual exige un espectador activo que no se duerma en la contemplación sino que ponga a trabajar su imaginación para, a partir de los datos ofrecidos en la obra, conocer por sí mismo el auténtico conflicto socioeconómico del barrio, diferente al que los poderes narraban $^{13}$. Y lo hace sin imponer un nuevo punto de vista, ya que la obra no explica cómo creía su autora que era realmente la situación, por lo que más que una representación es una «contrarepresentación» del barrio ${ }^{14}$.

10 ROSLER, M.: «Dentro, alrededor y otras reflexiones», p. 76, en RIBALTA, J. (ed.), Efecto real. Debates posmodernos sobre fotografía, Barcelona, Gustavo Gili, 2004, pp. 70-125.

11 Idem, pp. 93 y 96. Consultar también ROSLER, M.: Imágenes públicas..., pp. 17 y 24.

12 SEKULLA, A.: «Desmantelar la modernidad, reinventar el documental. Notas sobre la política de la representación», en RIBALTA, J.: op. cit., pp. 35-63.

13 ALBERRO, A.: «La dialéctica de la vida cotidiana: Martha Rosler y la estrategia del señuelo», $p$. 100, en DE ZEGHER, C.: op. cit., pp. 72-112.

${ }_{14}$ Recojo el término de Rosler, quien lo define por oposición a la imagen difundida por el poder. Ella recuerda la advertencia de Debord sobre la responsabilidad del productor de imágenes en una sociedad del espectáculo que se sirve de ellas. ROSLER, M.: «Si vivieras...», pp. 185 y 190-198. Consultar también ROSLER, M.: Imágenes públicas..., p. 27. 
Para ello, no sólo se sirvió de las imágenes sino también de textos. A las citadas estrategias visuales Rosler sumó un recurso lingüístico, introduciendo en la obra expresiones sobre el alcoholismo en su mayoría coloquiales y utilizadas por los propios borrachos del Bowery. Metáforas de un incipiente estado de borrachera entre imprudente y divertido que, según avanzamos en su lectura, se van recrudeciendo hasta mostrarlo peligroso. Así, podemos leer: empañado, doblado, plegado, torcido, borracho, tumbado, desencajado, inconsciente, tieso... En realidad, adjetivos que hemos escuchado otras veces y es que, al igual que hizo con la imagen, con el texto también partió de lo local para alcanzar lo global.

Cuatro razones la animaron a insertar texto en la obra. En primer lugar, pensó que las palabras le permitirían acercarse más objetivamente al universo de los alcohólicos al proceder muchas de ellos mismos, mientras que la imagen se acerca desde el exterior producida por alguien ajeno a esa experiencia y con una idea preconcebida sobre ella. Los propios borrachos solían autodesignarse con algunos de esos términos, por lo que era un sistema descriptivo que, en gran medida, procedía del interior del conflicto. Así, utilizó el lenguaje con la intención de equilibrar la tendencia a la subjetividad fruto de la mirada del fotógrafo. Pero terminó por observar que esas expresiones se habían popularizado tanto que se habían convertido en una manera de etiquetar a las víctimas.

En segundo lugar, Rosler declara que le interesaba facilitar el acceso a la obra. Creyó que debía eludir la imagen muda, cuya lectura a menudo requiere una familiaridad con el arte que pocos disfrutan. Pero, en la práctica, la inserción de estas palabras sueltas, que no constituyen una narración o descripción porque ni siquiera servirían para construir una sola frase, complicó aún más su interpretación. En cambio, lo que sí logró fue trasladar al espectador formado un papel más activo, pues esos textos e imágenes deben combinarse para producir significado. A partir de esta circunstancia, Rosler propuso su concepto de «representación participativa», que más tarde abordaremos.

En tercer lugar, con la inclusión de textos trataba de controlar el peligroso protagonismo de la imagen, que puede resultar entumecedora, y su tendencia a convertir la desgracia del otro en entretenimiento. Rosler observó cómo, a diferencia de aquellos reportajes que dejan la imagen trágica sola en manos de la curiosidad, los mejores exponentes del documental social se preocupan por asegurar su correcta interpretación contextualizando literalmente, es decir, arropando las imágenes con textos adecuados ${ }^{15}$. En este sentido, quiso ir más lejos aún, intentando que las fotografías fueran tan solo las ilustraciones del elemento principal: las palabras. Con dicha intención, decidió incluir sólo texto en las tres primeras piezas de la obra, confiando en que obligaría al observador a empezar leyendo ${ }^{16}$. Sin embargo, esto no resultó eficaz al diseñar la obra como un políptico dispuesto sobre la

15 Idem, p. 248. Consultar también ROSLER, M.: «Dentro, alrededor...», p. 113.

16 ROSLER, M.: Imágenes públicas..., pp. 11, 12 y 15. 
pared, ya que el espectador no puede evitar echar una rápida ojeada a las imágenes según se acerca a la instalación, antes de comenzar a leer. Sin duda, el recurso fue más útil las contadas veces en que decidió proyectar la obra como sucesión de diapositivas. Puesto que las tres primeras sólo contenían textos, era inevitable comenzar leyendo y la palabra entonces sí se imponía a la imagen. Sin embargo, sólo la mostró así en algunas ocasiones ${ }^{17}$.

Pero la cuarta razón por la que insertó esas expresiones fue la fundamental: resaltar su invalidez para referirse al barrio, pese a la insistencia con que eran utilizadas por la sociedad.

El propósito principal de Rosler al realizar esta obra fue poner en cuestión la imagen pública del Bowery, pues era utilizada por las autoridades para ilustrar su explicación del problema ${ }^{18}$. Para ello utilizó conjuntamente los mismos sistemas empleados en la construcción de esa imagen, las expresiones populares y la fotografía documental, de manera que se hiciera visible la inadecuación de ambos a consecuencia de su visión subjetiva.

Y no buscó un sistema más adecuado porque, como hemos visto, tampoco quería dar su punto de vista. Pero, sin restar valor a esa voluntad, ¿acaso lo hubiera encontrado?.

Una vez terminada, tituló la obra de modo que subraya ese fracaso de las expresiones populares y la fotografía documental. Pero también parece preguntar de esta manera cómo podría exponerse adecuadamente un conflicto social, que es experiencia, con herramientas de representación. Formular este interrogante sobre la capacidad del medio artístico es un propósito secundario en la obra ${ }^{19}$.

Un problema difícil de solucionar, pues la vida de los habitantes del Bowery pertenece al ámbito de la realidad, aparentemente opuesto al de las ficciones que produce el arte. Parece obligarnos a ignorar uno de los dos ingredientes: o intervenimos en la experiencia de la calle desde la acción social declarándonos activistas y olvidándonos de las representaciones; o nos quedamos con éstas en el terreno de la ficción desde donde, en principio, no podemos incidir en la realidad y, por lo tanto, constreñimos la experiencia limitándonos a representarla ${ }^{20}$. Precisamente en posiciones intermedias entre ambos extremos, se ha desarrollado durante años el debate suscitado a raíz de este problema que otros coincidieron con Rosler en detectar.

17 Proyectó la obra en una conferencia que impartió en el departamento de fotografía del Nova Scotia College. A propuesta del editor Benjamin Buchloh, que asistió al pase, surgió el libro ROSLER, M.: Three works, Nueva Escocia, N. S. College of Arts and Design Press, 1981, que reproducía la obra acompañada por su ensayo «Dentro, alrededor y otras reflexiones», escrito específicamente para esta edición.

18 ROSLER, M.: Imágenes públicas..., p. 10. Consultar también ROSLER, M.: «Dentro, alrededor...», p. 124.

19 El primero era propiciar un «contradiscurso», ahora se trataría más bien de un «metadiscurso». CANDELA, I.: op. cit., pp. 74-76 y 79.

20 BUCHLOH, B. y ROSLER, M.: op. cit., p. 45. 
Ella propuso la «representación participativa», que trata de aprovechar características de ambos inclinándose hacia la representación ${ }^{21}$. En cierta ocasión dijo que la función del «nuevo documental radical» debía ser exponer, militar, auto organizar o apoyar a los oprimidos. Con su obra sobre el Bowery optó claramente por exponer, manteniéndose escrupulosamente dentro del campo de la representación. Y es que, en su opinión, como artista no debe hacer directamente el cambio, sino propiciarlo. Rosler piensa que el documental sólo debería «movernos hacia» la acción política, y siempre tras una reflexión crítica previa que debería facilitar. No moralizar ni adoctrinar, sino únicamente levantar sospechas sobre la representación impuesta, sobrepuesta a la realidad, para que el público desvele ésta por su cuenta y actúe en consecuencia. Así, ella espera encontrar la manera de lograr repercusión en la realidad buscando aún en el ámbito de las ficciones.

Recientemente Brian Holmes, del colectivo Ne pas plier, ha sugerido una variante algo más cercana al extremo de la acción social con su «representación directa». Una línea de trabajo que para muchos excede los difusos límites del arte, pero que la misma Rosler tanteó en su proyecto de 1989 titulado If you lived here $[\ldots]^{2}$.

Claro que, si Rosler decidió mantenerse en el campo de la representación, no puede permitirse el lujo de desatender formalmente la obra, tal y como parecía proponer su «nuevo documental radical» con aquel desprecio por el momento estético de la foto. Pero la explicación de este aparente contrasentido la ofrece la misma Rosler en una entrevista que mantuvo con Benjamin Buchloh. Según dice, ella no renunció a los elementos formales, sino todo lo contrario, se sirvió de ellos para ofrecer esa estética que hemos analizado —improvisación, actualidad, objetividad, documentalismo, rigurosidad...- Es decir, no descuidó la estética, sino que dio una estética descuidada, que no es lo mismo.

Para su modelo de representación participativa Rosler siguió apostando concretamente por el documental, pero sabía que debía terminar con ese riesgo de comercialización de la tragedia que parece implicar y con las dudas sobre su capacidad crítica. Ya no valía con una simple actualización del género, como pretendió en el Bowery, sino que era necesario redefinirlo.

En los primeros años del siglo veintiuno, ella cree haber visto el documental finalmente renovado. Dejando los modos de producción y los canales de distribución tradicionales para la propaganda de poderes políticos y económicos, ahora puede

${ }^{21}$ Idem, p. 28. Consultar también ROSLER, M.: Imágenes públicas..., pp. 21 y ss, 210.

22 (No debe confundirse este proyecto artístico con su ensayo del mismo nombre.) Sobre el concepto de Holmes, él mismo lo define como «la capacidad de ofrecer herramientas para la auto-articulación de grupos diversos que las usan puntualmente para reclamar el espacio público.» HOLMES, B. y EXPÓSITO, M.: «Estéticas de la igualdad. Jeroglíficos del futuro», p. 360, en VV.AA.: Arte: La imaginación política radical, Brumaria, nº 5, Madrid, Asociación Cultural Brumaria, 2005, pp. 343-372. 
realizarse con vídeo digital doméstico y difundirse masivamente por Internet con sencillez y calidad a bajo coste ${ }^{23}$. Por lo tanto, parece que hoy podemos ocuparnos de la experiencia con ese nuevo medio de representación, pues no la constriñe sino — todo lo contrario- la amplifica, ya que mejora nuestra capacidad para promover cambios. Sin embargo Rosler, habiendo mostrado interés, no se ha servido de ellos en su nuevo acercamiento al barrio: Bowery High Lights (2008) ${ }^{24}$.

${ }^{23}$ Idem, pp. 361 y 368. Internet significa ya para Holmes la sustitución real del circuito artístico tradicional por redes de difusión constituidas entre productores y consumidores de cultura. Sobre el interés en socializar los medios de producción artística consultar BENJAMIN, W.: El autor como productor, México D.F., Itaca, 2004. También BOURRIAUD, N.: Postproducción, Buenos Aires, Adriana Hidalgo, 2004.

24 ROSLER, M.: Imágenes públicas..., pp. 207, 209 y 242. Consultar también CANDELA, I.: op. cit., p. 76. Y además BUCHLOH, B y ROSLER, M.: op. cit., pp. 31 y 42 . En su momento también le atrajo el uso que hacían de la foto los movimientos sociales, cómo relacionaban estética y activismo ignorando la institución artística y produciendo para un público no especializado, pero sólo quedó reflejado en algunos trabajos iniciales. Especialmente en los primeros fotomontajes de Bringing the war home (1967-72), que publicó en prensa alternativa para ponerlos al servicio de otros militantes en lugar de presentarlo en contextos artísticos. Aunque algún tiempo más tarde también fueron pasando a las galerías. ROSLER, M.: Imágenes públicas..., pp. 162. 
Cap17 14/11/2011 13:28 Página 394 